for a patient with renal failure. Lowered blood viscosity, which usually accompanies the anaemia of chronic renal failure, may prevent sluggish mesenteric blood flow in other patients undergoing dialysis who are subjected to similar haemodynamic stresses.

Digitalis should be considered as a possible cause when evaluating obscure abdominal pain in patients undergoing haemodialysis, who may benefit - and be rendered free of pain - when digitalis is withheld.

${ }^{1}$ Ross J, Waldhausen JA, Braunwald E. Studies on digitalis: direct effects on peripheral vascular resistance. $\mathcal{F}$ Clin Invest 1960;39:930-6.

2 Harrison LA, Blaschke J, Phillips RS, Price WE, Cotten MD, Jacobson ED. Effects of ouabain on the splanchnic circulation. F Pharmacol Exp Ther 1969;169:321-7.

${ }^{3}$ Shanbour LL, Jacobson ED, Brobmann GF, Hinshaw LB. Effects of ouabain on splanchnic hemodynamics in the rhesus monkey. $A m$ Heart 7 1971;81:511-5.

${ }^{4}$ Ferrer MI, Bradley SE, Wheeler HO, Ewson Y, Preisig R, Harvey RM. The effect of digoxin in the splanchnic circulation in ventricular failure. Circulation 1965;32:524-37.

${ }^{5}$ Gazes PC, Holmes CR, Moseley V, Pratt-Thomas HR. Acute hemorrhage and necrosis of the intestines associated with digitalization. Circulation $1961 ; 23: 358-64$.

(Accepted 3 fune 1980)

Departments of Medicine, Veterans Administration Medical Centre, and Downstate Medical Centre, Brooklyn, New York 11209, USA MARTIN FEINROTH, MB, PHD, fellow in nephrology

MARY V FEINROTH, MB, fellow in nephrology

A PETER LUNDIN, MD, assistant professor of medicin

ELI A FRIEDMAN, MD, FACP, professor of medicine

GEOFFREY M BERLYNE, MD, FRCP, professor of medicine

\section{Arthritis preceding fulminant ulcerative colitis and responding to colectomy}

Although it has long been recognised that ulcerative colitis may be complicated by bouts of arthritis, ${ }^{12}$ the clinical course of "colitic arthritis" has only recently been characterised. ${ }^{3}$ Large joints are usually affected in a flitting and asymmetrical way, most commonly in chronic ulcerative colitis, and in a series of 269 patients never preceded the onset of bowel symptoms. Colectomy invariably results in prolonged remission of arthritic symptoms. ${ }^{4}$ We describe a patient with colitic arthritis whose joint symptoms preceded bowel symptoms by five years and in whom the onset of colitis was acute and fulminant.

\section{Case report}

A 19-year-old woman presented in December 1978 with a four-year history of recurrent pain in her shoulders, elbows, wrists, and knees. Her general health was otherwise good with no bowel symptoms. There was tenderness over the ulnar heads and discomfort on moving the shoulders and knees but no other abnormality. Radiographs were normal. Results of routine haematological studies and tests for antinuclear factor were normal. The presumptive diagnosis was seronegative rheumatoid disease. She was given a six months' course of chloroquine phosphate and naproxen and remained fairly well over the next 15 months with only one exacerbation of soreness and stiffness of the right shoulder, which responded to a local hydrocortisone injection.

In January 1980 she became generally unwell with lethargy, weakness, and an exacerbation of pain and stiffness in her large joints. She developed bowel symptoms for the first time with lower abdominal pain and loose, watery bowel motions up to eight times daily, streaked with mucus and blood. Several stool cultures were sterile, and symptomatic treatment had little effect. On admission to hospital she was pale and dehydrated with a temperature of $38.5^{\circ} \mathrm{C}$, though her pulse and blood pressure were stable. There was no obvious swelling or inflammation around her large joints, but they were painful and stiff. She had generalised abdominal tenderness, particularly in the left iliac fossa, and bowel sounds were pronounced. Abdominal radiography showed a grossly dilated colon. Findings of routine haematological and serological studies were again normal. Her HLA type was subsequently reported as A2, B17, BW44, BW4 but not B27. Radiographs of her sacroiliac joints were normal.

Conservative treatment with intravenous fluids and high-dose corticosteroids produced a temporary initial response. Five days after admission, however, she developed severe abdominal pain with guarding and rebound tenderness, and bowel sounds disappeared. Abdominal radiography confirmed perforation of the bowel. At operation the whole colon was distended, inflamed, and oedematous and there were perforations in the caecum and sigmoid colon. She underwent total colectomy and terminal ileostomy. Since the rectum had looked relatively normal on sigmoidoscopy it was conserved. Histological examination showed extensive ulceration with focal crypt abscess formation, the appearances being typical of severe ulcerative colitis.

The patient made an excellent recovery, and five months later remained entirely free of joint symptoms without anti-inflammatory drugs.

\section{Comment}

The pattern of joint disease, exacerbation of symptoms with the onset of colitis, and dramatic response to colectomy confirm that this patient had colitic arthritis. ${ }^{3}$ The unique features, however, were the long history of joint symptoms preceding the onset of colitis and the acute fulminant mode of onset of colitis. Significant colitis was probably not present during the five years when no bowel symptoms existed, but perhaps the relatively simple investigation of sigmoidoscopy with rectal biopsy should be considered in recurrent undiagnosed seronegative arthropathy. It might then be possible to offer specific treatment for colitis with resultant control of joint symptoms and to hope to prevent severe colitis.

Requests for reprints should be sent to Dr David M Fraser.

${ }^{1}$ Bargen JA. Ten years' experience in treatment of chronic ulcerative colitis. Transactions of the American Gastroenterological Association $1933 ; 36: 49-60$

2 Hench PS, Bauer W, Boland E, et al. Rheumatism and arthritis. Review of American and English literature for 1940. Ann Intern Med 1941;15: 1002-108.

${ }^{3}$ Wright V, Watkinson G. The arthritis of ulcerative colitis. $\mathrm{Br} \mathrm{Med} \mathcal{F}$ 1965 ;ii: $670-5$.

${ }^{4}$ Brooke BN. Outcome of surgery for ulcerative colitis. Lancet 1956 ;ii: 532-6.

(Accepted 15 fuly 1980)

Milesmark Hospital, Rumblingwell, Dunfermline KY12 9NR

DAVID K MCCULLOCH, MRCP, registrar

DAVID M FRASER, MRCP, consultant physician

Dunfermline and West Fife Hospital, Dunfermline

ALLAN L TURNER, FRCS, consultant surgeon

\section{Successful pregnancy in severe chronic renal failure not requiring dialysis}

Chronic renal failure in women is usually associated with impaired fertility ${ }^{1}$ and a high incidence of miscarriage. ${ }^{23}$ In women with creatinine clearance below $10 \mathrm{ml} / \mathrm{min}$ successful pregnancy not requiring dialysis has not been recorded. We report such a case.

\section{Case report}

A 31-year-old Asian housewife had three full-term normal deliveries in 1968, 1969 , and 1974, during each of which her albuminuria was +++ . During the third pregnancy creatinine clearance was $133 \mathrm{ml} / \mathrm{min}$. She was normotensive during all three pregnancies. In June 1979, however, she presented to her GP with headache, and her blood pressure was $220 / 120 \mathrm{~mm} \mathrm{Hg}$. Oxprenolol $320 \mathrm{mg}$ daily reduced the blood pressure to $160 / 85 \mathrm{~mm} \mathrm{Hg}$ by October. In November 1979 (at 17 weeks of pregnancy) her blood pressure was $170 / 100 \mathrm{~mm} \mathrm{Hg}$. Her haemoglobin concentration was $7.6 \mathrm{~g} / \mathrm{dl}$, blood urea and creatinine concentrations $27 \mathrm{mmol} / 1(162.7 \mathrm{mg} / 100 \mathrm{ml})$ and 500 $\mu \mathrm{mol} / 1(5.7 \mathrm{mg} / 100 \mathrm{ml})$ respectively, proteinuria $3 \mathrm{~g} /$ day, and creatinine clearance $7.6 \mathrm{ml} / \mathrm{min}$. She was admitted to hospital and received a $40 \mathrm{~g}$ protein "no added salt" diet, transfused with 2 units of blood, and prescribed only methyldopa $250 \mathrm{mg}$ twice daily. Blood urea and creatinine concentrations rose slowly, though blood pressure and fetal growth were initially satisfactory.

On 12 February 1980 she was transferred to the Manchester Royal 